\title{
STRATEGI PENGEMBANGAN DAYA TARIK WISATA BALLA LOMPOA DI KABUPATEN GOWA PROVINSI SULAWASI SELATAN
}

\author{
Sulham Winarto \\ Pendidikan Administrasi Perkantoran, FIS, UNM \\ Risma Niswaty \\ Dosen Administrasi Perkantoran, FIS, UNM \\ Jamaluddin \\ Dosen Administrasi Perkantoran, FIS, UNM
}

\begin{abstract}
ABSTRAK
Penelitian ini bertujuan untuk mengetahui strategi pengembangan daya tarik wisata Balla Lompoa di Kabupaten Gowa. Penelitian ini bersifat deskriptif kualitatif. yaitu penelitian yang menggambarkan Strategi Pengembangan Daya Tarik Wisata Balla Lompoa di Kabupaten Gowa Provinsi Sulawesi Selatan. Adapun Informan dalam penelitian ini adalah Staff/Pegawai Negeri Sipil yang telah mengikuti pengembangan dalam hal ini Pendidikan dan Pelatihan serta staff pengelola yang ada di Balla Lompoa. Informasi yang didapatkan dari informan tersebut berupa keterangan mengenai pengembangan yang dilakukan terhadap Balla Lompoa. Hasil penelitian menunjukkan bahwa pengembangan Pariwisata Balla Lompoa yang telah dilakukan berjalan dengan baik dan sangat efektif. Dilihat dari beberapa pengembangan yang dilakukan seperti merevitalisasi Museum Balla Lompoa menjadi lebih menarik, dengan cara menaikan dasar atau pondasi dari bangunan Balla Lompoa setinggi $320 \mathrm{~cm}$, kegitan kebudayaan yang selalu dilaksanakan seperti Accera Kalompoang, upacara ganti jaga pasukan tubarania setiap bulannya, ma'udukan ri gowa atau maulid Nabi. Semua itu tidak lepas dari manajemen strategi yang dilakukan oleh Dinas Kebudayaan dan Pariwisata Kabupaten Gowa. Dinas Kebudayaan dan Pariwisata Kabupaten Gowa senantiasa mengevaluasi pengembangan-pengembangan yang dilakukan bukan hanya pada wisata Museum Balla Lompoa, namun kepada semua objek wisata yang ada di Kabupaten Gowa, sehingga Kabupaten Gowa dapat menjadi salah satu tempat destinasi wisata yang menarik untuk dikunjungi.
\end{abstract}

Kata kunci: Strategi Pengembangan Daya Tarik Wisata, Kabupaten Gowa Provinsi Sulawesi Selatan

\section{PENDAHULUAN}

Paradigma pembangunan dibanyak negara kini lebih berorientasi kepada pengembangan sektor jasa dan industri, termasuk di dalamnya adalah perkembangan industri pariwisata yang sangat pesat dan dapat memberikan peluang terhadap pertumbuhan ekonomi nasional maupun regional. Dalam hal ini Indonesia merupakan salah satu negara yang memiliki potensi Obyek Dan Daya Tarik Wisata (ODTW) berupa keanekaragaman hayati yang sangat tinggi yang berupa sumber daya alam yang berlimpah, baik di daratan, udara maupun di perairan, keunikan 
Sulham Winarto, Risma Niswaty, Jamaluddin: Strategi Pengembangan Daya Tarik Wisata Balla Lompoa |95

dan keaslian budaya tradisional, keindahan bentang alam, gejala alam, peninggalan sejarah/budaya.

Berdasarkan hasil observasi awal peneliti dari Dinas Kebudayaan dan Pariwisata Kabupaten Gowa, selama 3 tahun terakhir Museum Balla Lompoa mengalami penurunan jumlah kunjungan wisatawan, seperti yang dapat dilihat pada kunjungan wisatawan Kabupaten Gowa Provinsi Sulawesi Selatan tahun 2012-2014.

Berdasarkan hasil pengamatan peneliti pada kantor Dinas Kebudayaan dan Pariwisata Kabupaten Gowa dan data kunjuangan wisatawan yang ada serta uraian di atas maka dapat dirumuskan permasalahan pada penelitian ini difokuskan untuk menganalisa dan menentukan strategi-strategi yang perlu ditempuh dalam pengembangan pariwisata daerah Kabupaten Gowa.

Menurut Barry dalam Tripomo (2005: 17) menyatakan bahwa: "Strategi adalah rencana tentang apa yang ingin dicapai atau hendak menjadi apa suatu organisasi di masa depan (arah) dan bagaimana cara mencapai keadaan yang diinginkan tersebut (rute)". Sedangkan menurut Tripomo (2005: 17) "Strategi adalah kerangka atau rencana yang mengintegrasikan tujuantujuan (goals) kebijakan-kebijakan (policies), dan tindakan-tindakan/program (programs) organisasi".

Manajemen strategik merupakan suatu proses yang dinamik karena berlangsung secara terus-menerus dalam suatu organisasi. Setiap strategi selalu memerlukan peninjauan ulang dan bahkan mungkin perubahan di masa depan. Salah satu alasan utama mengapa demikian halnya ialah karena kondisi yang dihadapi oleh satu organisasi, baik yang sifatnya internal maupun eksternal selalu berubah-ubah pula. Dengan kata lain strategi manajemen dimaksudkan agar organisasi menjadi satuan yang mampu menampilkan kinerja tinggi karena organisasi yang berhasil adalah organisasi yang tingkat efektifitas dan produktivitasnya makin lama makin tinggi.

Menurut Wheelen dan Hunger dalam Solihin (2004: 83) proses manajemen strategi mencakup perumusan strategi, implementasi strategi, serta evaluasi dan pengendalian. Wheelen dan hunger menggambarkan proses strategi manajemen yaitu Tahap Environmental Scanning, Tahap Strategi Formulation, Tahap Implementasi, Tahap Evaluation and Control. Sedangkan menurut Mintzberg dalam Agustinus (1996: 20) menyimpulkan bahwa terdapat tiga model pembuatan strategi, yaitu: Model Entrepreneur/Cara Wirausaha (Entrepreneurial Mode), Model Penyesuaian/Cara Adaptif (Adaptive Mode), Model Perencanaan/Cara Perencanaan (Planning mode).

Pariwisata merupakan kegiatan yang dapat dipahami dari banyak pendekatan. Dalam undang-undang RI nomor 10 tahun 2009 tentang kepariwisataan di jelaskan bahwa Pariwisata adalah "Berbagai macam kegiatan wisata dan didukung berbagai fasilitas serta layanan yang disediakan oleh masyarakat, pengusaha, pemerintah, dan Pemerintah Daerah".

Menurut Undang-Undang Republik Indonesia No. 10 tahun 2009 tentang kepariwisataan di jelaskan bahwa, Daya Tarik Wisata adalah segala sesuatu yang memiliki keunikan, keindahan, dan nilai yang berupa keanekaragaman kekayaan alam, budaya, dan hasil buatan manusia yang menjadi sasaran atau tujuan kunjungan wisatawan. 
Daya tarik wisata menurut Direktoral Jendral Pemerintahan dibagi menjadi tiga macam, yaitu : Daya Tarik Wisata Alam, Daya Tarik Wisata Sosial Budaya, Daya Tarik Wisata Minat Khusus.

Pengembangan pariwisata merupakan suatu proses yang dinamis dan berkelanjutan menuju ketataran nilai yang lebih tinggi dengan cara melakukan penyesuaian dan koreksi berdasar pada hasil monitoring dan evaluasi serta umpan balik implementasi rencana sebelumnya yang merupakan dasar kebijaksanaan dan merupakan misi yang harus dikembangkan. Pembangunan pariwisata memerlukan modal, modal ini dapat berasal dari pemerintah maupun swasta. Dalam situasi di mana pemerintah terpaksa harus bekerja dengan sumber daya yang amat terbatas, sangatlah diharapkan pihak swasta dapat berperan lebih besar dengan ikut mendanai pembangunan berbagai prasarana, terutama yang berkaitan langsung dengan pembangunan objek atau tujuan wisata.

\section{KAJIAN TEORI}

\section{Manajemen Strategi}

Manajemen strategik merupakan suatu proses yang dinamik karena berlangsung secara terus-menerus dalam suatu organisasi. Setiap strategi selalu memerlukan peninjauan ulang dan bahkan mungkin perubahan di masa depan. Salah satu alasan utama mengapa demikian halnya ialah karena kondisi yang dihadapi oleh satu organisasi, baik yang sifatnya internal maupun eksternal selalu berubah-ubah pula. Dengan kata lain strategi manajemen dimaksudkan agar organisasi menjadi satuan yang mampu menampilkan kinerja tinggi karena organisasi yang berhasil adalah organisasi yang tingkat efektifitas dan produktivitasnya makin lama makin tinggi.

Menurut Nisjar, Karhi \& Winardi. (1997: 85) bahwa manajemen strategik mengatakan bahwa: "Manajemen strategik adalah proses mengelola strategi yang terdiri dari tahapan perumusan - implementasi-evaluasi/pengendalian-perbaikan strategi, dengan tujuan agar strategi dapat diimplementasikan sehingga mewarnai dan mengintegrasikan semua keputusan dan tindakan dalam organisasi”. Kata kunci dalam ungkapan di atas tidak terlepas dari kata strategi itu sendiri, misi, objektif, serta kapabilitas internal dan eksternal. Proses manajemen strategis menuntut para manajer untuk memeriksa dan mengontrol situasi lembaga atau perusahaannya secara periodik, mengevaluasi misi dan tujuanya, menilai lingkungan eksternalnya ditinjau dari sudut situasi ekonomi, perubahan struktur, kompetisi, inovasi teknologi di samping menilai kemampuannya ke dalam, seperti sumber daya manusianya, kualitas produksi atau luarannya, keterampilan dan teknik-teknik pemasarannya serta performan keuangan. 
Sulham Winarto, Risma Niswaty, Jamaluddin: Strategi Pengembangan Daya Tarik Wisata Balla Lompoa |97

\section{Daya Tarik Wisata}

Menurut Undang-Undang Republik Indonesia No. 10 tahun 2009 tentang kepariwisataan di jelaskan bahwa, Daya Tarik Wisata adalah segala sesuatu yang memiliki keunikan, keindahan, dan nilai yang berupa keanekaragaman kekayaan alam, budaya, dan hasil buatan manusia yang menjadi sasaran atau tujuan kunjungan wisatawan. Daya tark wisata adalah suatu objek ciptaan Tuhan maupun hasil karya manusia, yang menarik minat orang untuk berkunjung dan menikmati keberadaannya. Menurut Yoeti (2008: 15) mengatakan bahwa semua objek dan atraksi yang tersedia sebagai daya tarik mengapa wisatawan mau datang berkunjung ke negara, kota atau daya tari tersebut. Termasuk dalam kelompok ini yaitu: natural recources, cultur recources, theme parks, sport acvtities dan event. Berdasarkan Peraturan Pemerintah No. 50 tahun 2011 tentang RIPPARNAS mengatakan bahwa Daya Tarik Wisata adalah segala sesuatu yang memiliki keunikan, keindahan, dan nilai yang berupa keanekaragaman kekayaan alam, budaya, dan hasil buatan manusia yang menjadi sasaran atau tujuan kunjungan wisatawan.

\section{METODE PENELITIAN}

Penelitian ini merupakan jenis penelitian kualitatif dengan menggunakan pendekatan deskriptif kualitatif yang menggambarkan tentang permasalahan yang dikaji, dengan menggunakan metode ini diharapkan dapat memberikan gambaran tentang strategi pengembangan daya tarik wisata Museum Balla Lompoa di Kabupaten Gowa kepada masyarakat umum. Lokasi penelitian dilakukan di Dinas Kebudayaan dan Pariwisata Kabupaten Gowa, Provinsi Sulawesi Selatan yang terletak di Jl. Masjid Raya No. 30 Gedung C lantai 2.

Adapun jenis data yang digunakan pada penelitian ini adalah jenis data kualitatif yaitu jenis data yang berbentuk kata-kata atau yang berwujud pernyataan-pernyataan verbal, bukan dalam bentuk angka. Adapun sumber data yang digunakan adalah data primer dan sekunder. Menurut Sugiyono (2012:139) Sumber data, yaitu:

a) Data Primer adalah sumber data yang langsung memberikan data kepada pengumpul data. Penelitian ini dilakukan pengamatan secara langsung dengan melakukan tehnik wawancara kepada pihak pengelolah termasuk pemerintah Dinas Kebudayaan dan Pariwisata Kabupaten Gowa. Salah satu data primer yang dibutuhkan seperti daftar jumlah kunjungan wisatawan di Kabupaten Gowa, struktur kepegawaian Dinas Kebudayaan dan Pariwisata Gowa, serta beberapa file seperti RENJA dan RENSTRA 2010-2015.

b) Data Sekunder adalah sumber data yang diperoleh dengan cara membaca, mempelajari dan memahami melalui media lain yang bersumber dari literatur, buku-buku, serta dokumen dari pemerintah. Dari beberapan data sekunder tersebut akan dijadikan sebagai sumber data yang akan menunjang dalam penelitian yang dilakukan. 
Instrument utama adalah peneliti sendiri dengan menggunakan alat bantu Tape recorder sebagai alat perekam, Kamera Digital, dan menggunakan catatan lapangan yaitu dengan mencatat data-data yang terkait dengan penelitian yang ditemukan dilapangan.

Teknik analisis data dalam penelitin ini melalui tahapan dan langkah-langkah menurut model Miles and Huberman (Sugiyono, 2003: 337), seperti: a) Pengumpulan Data, b) Reduksi Data, c) Penyajian Data, d) Verifikasi Data. Dalam hal ini, hasil penelitian peneliti didukung oleh data-data yang lengkap sehingga menghasilkan kesimpulan yang kredibel. Sebelum dianalisis, data terlebih dahulu diolah secara ringkas dan sistematis. Pengolahan data adalah proses penyusunan (yang dimulai dari menulis hasil pengamatan, wawancara, mengklasifikasi, mereduksi, dan menyajikan) data agar dapat ditafsir dan dianalisis secara deduktif.

Jadi analisis data yang digunakan untuk menganalisis data hasil wawancara, observasi maupun dokumentasi adalah analisis deskriftif kualitatif, sehingga analisis data hasil penelitian bersifat naratif atau menceritakan secara factual kondisi objektif pada wisata sejarah Museum Balla Lompoa yang berkaitan dengan bagaimana strategi pengembangannya.

\section{HASIL PENELITIAN DAN PEMBAHASAN}

Dalam pengembangan Museum Balla Lompoa tidak lepas dari peran para stekholder baik itu pemerintah, pemangku adat, tokoh adat, dan tokoh masyarkat. Oleh karena itu upayaupaya yang akan dilakukan dalam pengembangan Museum Balla Lompoa dilakukan melalui hasil musyawarah atau masukan dari sejumlah pihak-pihak yang terkait. Hal ini dilakukan karena masing-masing pihak memilki wewenan pada Museum Balla Lompoa, tetapi peran pemerintah lebih besar pengaruhnya. Dilihat dari status Museum Balla Lompoa yang merupakan milik pemerintah dalam hal ini adalah Dinas Kebudayaan dan Pariwisata Kabupaten Gowa yaitu mengatur, melestarikan, menata, dan memberikan biaya oprasional.

Selain itu pengembangan dilakukan dengan menjadikan Museum Balla Lompoa sebagai pusat atraksi budaya yang sampai saat ini masih dilakukan sepanjang tahun yakni upacara adat accera kalompoang, upacara adat penyambutan dan penjamuann tamu-tamu kenegaraan, upacara ganti jaga pasukan tubarania setiap bulannya, ma'uduka ri gowa atau maulid nabi. Selain itu dilakukan pula pembersian benda pusaka setiap bulannya.

Dalam pengembangan Museum Balla Lompoa pemerintah kabupaten Gowa khususnya Dinas Kebudayaan dan Pariwisata tentunya perlu menggunakan manejeman strategi yang tepat untuk mengembangkan Museum Balla Lompoa menjadi salah satu destinasi wisata yang menarik sehingga dapat mendatangkan banyak wisatawan lokal maupun wisatawan asing, berdasarkan hal tersebut, Dinas Kebudayaan dan Pariwisata perlu memperhatikan beberapa hal dalam melakukan pengembangan daya tarik wisata Museum Balla Lompoa berdasarkan uaraian hasil penelitian, diantaranya:

1. Perencanaan dan Perumusan Strategi (Planning), Sebelum Museum Balla Lompoa dikembangkan, pihak pemerintah Kabupaten Gowa yakni Dinas Kebudayaan dan Pariwisata Kabupaten Gowa telah menyusun dan merumuskan pengembangan seperti apa yang akan mereka lakukan serta bagaimana cara mereka melakukan pengembangan tersebut. Dari pengembangan tersebut tentunya pihak pemerintah Kabupaten Gowa khususnya Dinas 
Sulham Winarto, Risma Niswaty, Jamaluddin: Strategi Pengembangan Daya Tarik Wisata Balla Lompoa|99

Kebudayaan dan Pariwisata Gowa sebelumnya telah merumuskan dan merencanakan pengembangan tersebut dengan baik. Sebelum melakukan sebuah pengembangan terhadap Museum Balla Lompoa, Dinas Kebudayaan dan Pariwisata Kabupaten Gowa akan mengadakan rapat pertemuan yang dihadiri oleh para pemangku adat, tokoh-tokoh adat. Dalam rapat tersebut dipaparkan masalah apa yang akan dihadapi dan bagaimana solusinya sehingga pengembangan dapat berjalan dengan baik.

2. Implementasi Strategi (Doing), Pada tahap ini solusi yang ada di kumpulkan lalu dipilih satu solusi yang tepat dan relevan dengan masalah yang ada. Setelah itu solusi tersebut diimplementasikan atau diterapkan. Pelaksanaan pengembangan daya tarik itu hanya terfokus pada bangunan Museum Balla Lompoa saja namun juga pada kawasan Museum Balla Lompoa, contohnya seperti pelataran Museum, taman-taman, serta kegiatan kebudayaan yang tiap tahunnya dilaksanakan.

3. Evaluasi dan Pengendalian Strategi (Controling/Check), Pada tahap ini proses pengecekan, memantau dan mengukur proses dari hasil yang terjadi apakah sesuai dengan rencana mutu, sasaran mutu, persyaratan produk yang telah ditetapkan, kemudian mengevaluasi dan melaporkan hasilnya. Melihat dari hasil pengembangan yang telah dilakukan oleh Dinas Kebudayaan dan Pariwisata Kabupaten Gowa telah berjalan dengan baik dan efektif maka mereka pun kemudian menyiapkan tindakan selanjutnya untuk meningkatkan daya tarik wisata Museum Balla Lompoa yaitu dengan cara mengundang seluruh sanggar tari yang ada di Gowa untuk berlatih di kawasan Museum Balla Lompoa.

\section{PENUTUP}

Berdasarkan hasil penelitian tentang Strategi Pengembangan Daya Tarik Wisata Museum Balla Lompoa di Kabupaten Gowa Provinsi Sulawesi Selatan dapat disimpulkan bahwa Konsep PDCA (Planning-Doing-Contoling/Check-Actuating) yang pada hakekatnya merupakan siklus yang pada implementasinya dimaksudkan untuk membangun budaya berbasis perbaikan terus menerus menjadi salah satu strategi yang digunakan dalam pengembangan daya tarik wisata yang dilakukan oleh Dinas Kebudayaan dan Pariwisata Kabupaten Gowa dan salah satunya penerapanya yaitu merevitalisasi Museum Balla Lompoa menjadi lebih menarik, dengan cara menaikan dasar atau pondasi dari bangunan Balla Lompoa setinggi $320 \mathrm{~cm}$, kegitan kebudayaan yang selalu dilaksanakan seperti Accera Kalompoang, upacara ganti jaga pasukan tubarania setiap bulannya, ma'udukan ri gowa atau maulid Nabi. Semua kegiatan tersebut dapat dijadikan sebagai daya tarik wisata, bukan hanya itu saja pelataran kawasan Museum Balla Lompoa pun dibuat lebih indah salah satunya menggunakan marmer sebagai alas dari pelataran, pembuatan panggung di tengah-tengah kawasan Museum Balla Lompoa serta kolam ikan yang diharapkan dapat menambah kesan anggun dari Museum Balla Lompoa sehingga dapat menarik banyak wisatawan untuk berkunjung di tempat tersebut. 
100| Ad'ministrare, Vol. 2 No. 2, Juli - Desember 2015

\section{DAFTAR PUSTAKA}

Arsyad, Azhar, 2003. Manajemen Pengetahuan Praktis Bagi Pimpinan \& Eksekutif, Manajemen Strategik. Yogyakarta: Pustaka Pelajar

Dirgantoro, Crown, 2001. Manajemen Strategik Konsep, Kasus, dan Implementasi. Jakarta: Gramedia

Hunger, J. David dan Wheelen, Thomas L. 2003. Manajemen Strategis. Yogyakarta: Andi

Karyoso, 2005. Manajemen Perencanaan dan Penganggaran. Jakarta: PTIK Press dan Restu Agung

Kodyat, RA. 2001. Statistik Induktif Terapan. Yogyakarta: BPFE UGM

Mill, Robert Christie. 2000. Tourism The International Business. Jakarta: PT Raja Grafindo

Nisjar, Karhi \& Winardi. 1997. Manajemen Strategik. Bandung: MANDAR MAJU

Peraturan Pemerintah No.50 tahun 2011 tentang Rencana Induk Pembangunan Nasional

R.David, Fred. 2006. Manajemen Strategik Konsep. Jakarta: Salemba Empat

Siagian, Sondang P. 2005. Manajemen Stratejik. Jakarta: Bumi Aksara

Sugiyono, 2012. Metode Penelitian Kuantitatif, Kualitatif dan R\&D. Bandung: Alfabeta.

Solihin, Ismail. 2009. Pengantar Manajemen. Jakarta: Erlangga

Suswantoro, Gamal, SH. 2004. Dasar-Dasar Pariwisata, Yogyakarta: ANDI OFFSET

Tripomo, Tedjo, 2005. Manajemen Strategi. Jakarta: Rekayasa Sains

Umar, Husein. Dr. 2010. Desain Penelitian Manajemen Strategik. Jakarta: PT Raja Grafindo Persada.

Wahyudi, Agustinus Sri, 1996. Manajemen Strategik "Pengantar Proses Berfikir Strategik". Jakarta: Binarupa Aksara

Yoeti, OKA.A. 2008. Pengantar Ilmu Pariwisata. Bandung: Aksara

Undang-Undang Republik Indonesa Nomor 10 Tahun 2009 tentang Kepariwisataan Pendidikan. Bandung: Alfabeta. 